\title{
Prácticas de enseñanza en el aula, voz docente y políticas educativas: el caso del Programa de Español para la Educación Primaria en Costa Rica
}

\author{
Teaching Practices in Classrooms, Teacher Voices, and \\ Educational Policies: The Case of the Spanish Language \\ Program for Primary Education in Costa Rica
}

Paulette Barberousse-Alfonso

Universidad Nacional Heredia, Costa Rica paulette1959@yahoo.com

Marie-Claire Vargas-Dengo

Universidad Nacional

Heredia, Costa Rica marie_d_claire@yahoo.com https://orcid.org/0000-0001-8468-9690

Silvia Ulate-Carballo

Universidad Nacional

Heredia, Costa Rica sylauc8123@gmail.com

Viviana Rodríguez-Córdoba

Universidad Nacional

Heredia, Costa Rica

vivi_0495@hotmail.com

Recibido: 22/06/2020 • Aceptado: 09/09/2020 
Revista Universidad en Diálogo • Vol. 11, N. ํ 1, Enero-Junio, 2021 • 61-102

ISSN 2215-2849 • EISSN: 2215-4752

URL: http://www.revistas.una.ac.cr/index.php/dialogo/index CorReo ElECTRÓNICO: universidadendialogo@una.cr DOI: http://doi.org/10.15359/udre.11-1.3

Resumen. Este artículo se elabora desde el proyecto Prácticas de enseñanza en el aula, la voz docente y políticas educativas: alteraciones al formato escolar, adscrito a la División de Educación Básica (DEB) del Centro de Docencia e Investigación en Educación (CIDE), de la Universidad Nacional (UNA) en Costa Rica. Desde el quehacer de docencia-extensión, este proyecto guarda una relación directa de continuidad temática y operativa con el proyecto integrado titulado Construyendo una propuesta de implementación del Programa Maestros Comunitarios (2016-2018), que implementó las cinco líneas de trabajo del PMC en la Escuela Finca Guararí de Heredia, atendiendo a 174 niñas y niños en situación de vulnerabilidad educativa, con la participación de 58 estudiantes de los bachilleratos y las licenciaturas de las carreras de Pedagogía con Énfasis en I y II Ciclos y de Educación Especial, además de la participación de 21 maestras y maestros de I Ciclo y Aula Edad.

Precisamente por las incidencias y los cambios que se han generado en dicha escuela, a raíz de los procesos de implementación del PMC en el formato y la gramática escolar (tiempos, espacios, estrategias y dispositivos de mediación y evaluación pedagógica), es que se evidenciaron las directrices y los propósitos de la actual propuesta, que intenta identificar los puntos de encuentro y desencuentro entre las prácticas educativas de aula (mediaciones pedagógicas) en I y II Ciclos de la Educación General Básica, las voces de los y las docentes y las políticas educativas y curriculares vigentes del Ministerio de Educación Pública (MEP) en lo referente a los cuatro programas y las áreas básicas de aprendizaje, a saber, Español, Estudios Sociales, Ciencias y Matemáticas.

En esta primera entrega, y dada la especificidad y naturaleza de cada área del saber, nos centraremos en el Programa de Español vigente para I y II Ciclos. El abordaje metodológico, si bien se sustenta en los planteamientos y diseños investigativos generales de la investigación-acción (I-A), elige una óptica hermenéutica, ya que busca sentidos y significados a partir del análisis interpretativo de la realidad, de la información observada y recabada en interacción con los sujetos participantes.

Los retos y desafíos que enfrenta la enseñanza de la lectoescritura en nuestras aulas de primaria, a partir de los hallazgos del Séptimo Informe del Estado de la Educación-2019, sirven como encuadre de referencia para imbricar las opiniones y creencias de las y los docentes que imparten la materia en nuestras aulas. La adquisición de la lectoescritura en los primeros años de primaria constituye la puerta de entrada al currículo escolar, de ahí su trascendencia e importancia. Sin saber leer y escribir no se accede, ni remotamente, a la cultura contemporánea.

Palabras clave: extensión universitaria, prácticas de enseñanza, planes de estudio, formación docente, Educación General Básica.

Abstract: This paper is elaborated within the project titled Teaching practices in classrooms, teacher voices, and educational policies: changes to school format. It is assigned to the Basic Education Division (DEB) of the Center for Teaching and 
URL: http://www.revistas.una.ac.cr/index.php/dialogo/index

CORREO ELECTRÓNICO: universidadendialogo@una.cr

DOI: http://doi.org/10.15359/udre.11-1.3

Research in Education (CIDE) at the National University (UNA) of Costa Rica. From the teaching-extension work, this project has a direct relationship of thematic and operational continuity with the integrated project titled Building a proposal for implementing the community teachers program (2016-2018); this project implemented five working lines in the School Finca Guararí in Heredia, assisted 174 children in a vulnerable educational situation, and had the participation of 58 university students from the programs of Pedagogy with a major in I \& II cycles and Special Education, besides 21 teachers from I Cycle and Age ClassroomBecause of the modifications and changes the integrated project made, we have attempted to identify the meeting points between teaching classroom practices (pedagogical mediation) in the Elementary School in I \& II cycles, teachers' voices, and current educational curricular policy from the Costa Rican Ministry of Public Education (MEP) regarding four teaching programs and basic learning areas: Spanish, Social Studies, Sciences, and Math. In this paper, we address the current Spanish program for I \& II cycles. The foundation of the methodological approach concerns Action-Research (A-R) design with a hermeneutic view searching to find meanings and significance from the interpretative analysis of reality and the observed and gathered information from the interaction with participants. The 7th State of the Education Report 2019 frames Spanish classroom teachers' opinions and beliefs faced and challenged by the teaching of reading and writing within the Elementary School classrooms. Learning to read and write within the first school years is the entrance door to the school curriculum, hence its transcendence and importance. Without learning to read and write the access to modern culture is denied.

Keywords: university extension, teaching practices, study programs, teaching training, elementary school.

..a la hora del naufragio y de la oscuridad alguien te rescatará para ir cantando...

Como la cigarra - María Elena Walsh (1930-2011)

\section{Introducción}

Partimos del siguiente propósito general: identificar los puntos de encuentro y desencuentro entre las prácticas educativas de aula en I y II Ciclos de la Educación General Básica, las voces de las personas docentes y las políticas educativas y curriculares vigentes. Es decir, entre las macropolíticas educativas y las microrrealidades de las prácticas escolares en las aulas, específicamente entre los procesos de transformación curricular encarnados en los nuevos 
Revista Universidad en DiÁlogo • Vol. 11, N. ${ }^{\circ}$ 1, Enero-Junio, 2021 • 61-102

ISSN 2215-2849 • EISSN: 2215-4752

URL: http://www.revistas.una.ac.cr/index.php/dialogo/index CorReo ElECTRÓNICO: universidadendialogo@una.cr DOI: http://doi.org/10.15359/udre.11-1.3

programas de estudio de las materias básicas y las prácticas de enseñanza que asumen la voz de los docentes como actores protagónicos del proceso en el contexto y las coordenadas de nuestra realidad educativa nacional.

En este sentido, y tal como lo señala Pérez-Gomar (2013): "Las prácticas escolares...son entendidas como aquellas prácticas institucionalizadas, normadas, disciplinadas, situadas, sociales, culturales que también son prácticas educativas pero que lo escolar restringe" (p. 151).

De acuerdo con el autor, nos estaremos situando primordialmente en la lógica de entender, de la manera más compleja posible, las relaciones entre la experiencia vivida, situada y sentida con el saber que se produce en el encuentro del aula, en el marco de la relación pedagógica, en la voz y en las narrativas de las principales personas protagonistas, las maestras y los maestros. Toda escuela, según su opinión, detenta sus propias normas, tradiciones, costumbres y rituales.

Flavia Terigi (2006) remite al constructo de formato escolar como aquel que deja marcas que permiten organizar las formas de la escuela. Asume la autora que toda la vida escolar, su cultura y rutinas se encuentran condicionadas por dicho formato e impregna los significados y sentidos de las experiencias que en ella suceden todos los días.

Es bien sabido que todo proyecto curricular es un proyecto político y cultural. Nos situaremos en el campo de las estrategias de las mediaciones pedagógicas y de las prácticas de enseñanza para rescatar la voz de las personas docentes, ya que son las que cotidianamente se enfrentan a la tarea de educar. Y partimos, tal como lo señala Forteza (2017), de dos certezas que creemos incuestionables: "La certeza de la educabilidad y la del potencial de la praxis" (p. 126).

Todo proceso de cambio, como el que propone el MEP en este caso, genera múltiples tensiones al interior de la escuela y trastoca su cultura organizativa, sus cotidianidades. Cambian formatos, relaciones, rutinas. Asumimos, por otra parte, que el marco filosófico conceptual de las nuevas políticas y directrices del Ministerio de Educación Pública nos obligan a debatir sobre nuevas categorías de análisis, tales como: calidad educativa, paradigma de la complejidad, constructivismo social pedagógico, humanismo, transformación curricular, entre otras, que constituyen los fundamentos teórico-conceptuales y las expresiones particulares que conforman, en su conjunto, la Política Educativa Pública del Estado costarricense y se materializa en disposiciones, cambios normativos e innovaciones. 
En este sentido, la nueva política educativa de noviembre del 2017, aprobada por Conare, denominada La persona: centro del proceso educativo y sujeto transformador de la sociedad asume que:

...una política educativa, como documento público, de un país que desde la educación tiene una función estratégica al sustentar una política de Estado establece marcos referenciales que permitan vislumbrar el futuro promisorio de un país que desde la educación se propone avanzar hacia el cumplimiento de sus metas de mediano y largo plazo así como responder a los compromisos internacionales libremente asumidos. (p. 8)

Como bien lo señala Pérez-Gomar (2013), todo cambio educativo, toda "alteración" de las prácticas escolares, constituye el eje alrededor del cual giran las intencionalidades de las políticas educativas. La complejidad de las realidades sociales y, por consiguiente, de las escolares está "atravesada" por múltiples significados, sentidos y prácticas que reflejan diversas concepciones educativas y pedagógicas, no pocas veces antagónicas.

Recuperar la voz de las personas docentes en este panorama resulta, cuando menos, insoslayable. No ocurre en forma automática ni simultánea: una nueva política educativa requiere espacio y tiempo para realmente calar en la realidad de las aulas, para que los y las protagonistas se apropien de su guion y se comience a transitar del proclamar al hacer y vivenciar. Aunque para ser más claros, las políticas educativas deberían partir y tomar como insumos fundantes la voz, las opiniones y las creencias de sus principales protagonistas.

En el caso del Programa de Español que nos convoca, debemos enmarcarlo sin duda en el contexto de transformación curricular en relación directa con el documento titulado Fundamentación pedagógica de la transformación curricular: educación para una nueva ciudadanía (2016), promulgado por el Viceministerio Académico del Ministerio de Educación Pública (MEP). Debemos remarcar, en primera instancia, una serie de ideas-fuerza que lo estructuran y se basan en la educación entendida como un derecho humano y como un bien público. La propuesta asume que los procesos educativos buscan la formación de personas críticas y creativas, que "se aceptan y respetan a sí mismas y a las demás personas en cuanto a diferencias culturales, étnicas, de género, orientación sexual y religiosa; y al medio ambiente". Plantea que los pilares para la nueva ciudadanía se sustentan según el documento aludido:

a. Educación para el Desarrollo Sostenible: Idea originada en la década de los ochenta ante la preocupación por los recursos finitos del mundo, aunada 
Revista Universidad en DiÁlogo • Vol. 11, N. ${ }^{\circ}$ 1, Enero-Junio, 2021 • 61-102

ISSN 2215-2849 • EISSN: 2215-4752

URL: http://www.revistas.una.ac.cr/index.php/dialogo/index CoRreo ElECTRÓNICO: universidadendialogo@una.cr DOI: http://doi.org/10.15359/udre.11-1.3

al concepto de desarrollo sostenible, descrito en 1987 en el Informe de la Comisión de Bruntland "Nuestro futuro Común". El desarrollo sostenible (DS) es el eje fundamental de este planteamiento y se incluye en cuatro dimensiones, a saber: 1. En los contenidos de aprendizaje, 2. en la mediación pedagógica y los ambientes para el aprendizaje activo, 3. en los resultados de aprendizaje y, por último, 4 . en la transformación social.

b. Ciudadanía digital con equidad social: Conjunto de prácticas para disminuir la brecha social y digital mediante las TIC. Este concepto surge en el debate internacional y se encuentra en constante cambio. Se define como las normas de comportamiento concernientes al uso de la tecnología, involucra también la comprensión de asuntos humanos, culturales, económicos y sociales relacionados con las TIC.

c. Ciudadanía planetaria con identidad nacional: Propone "fortalecer y reconocer nuestra memoria histórica, ser conscientes de quiénes somos, de dónde venimos y a dónde vamos" (Unesco, 2015), y se refiere a que el mundo globalizado requiere habilidades, valores, actitudes, capacidades comunicativas y conocimientos cambiantes y dinámicos para resolver problemas sociales, políticos y culturales. Hace alusión a la "conexión e interacción inmediata entre personas en todo el mundo, lugar y momento", más allá de las fronteras y por avances en tecnologías móviles. Enfatiza que su definición está aún en construcción.

A su vez, asume tres dimensiones conceptuales: a. Cognitiva, b. socioemocional y c. conductual, y plantea cuatro retos principales:

a. La formación continua de las personas que integran la comunidad educativa (programa de capacitación en el MEP, actualización 2015-2018)

b. La mediación pedagógica para la construcción de conocimientos

c. El fomento de ambientes de aprendizaje diversos

d. La evaluación formativa y transformativa

La estructura para tal fin tiene cuatro dimensiones (D) y habilidades para el desarrollo educativo, organizadas por ciclo desde el preescolar hasta el ciclo diversificado, a saber:

a. D 1: Formas de pensar. Referido al desarrollo cognitivo, a la generación del conocimiento, a la resolución de problemas, a la creatividad, a la innovación y al estímulo del pensamiento crítico y sistémico. 
URL: http://www.revistas.una.ac.cr/index.php/dialogo/index

CORREO ELECTRÓNICO: universidadendialogo@una.cr

DOI: http://doi.org/10.15359/udre.11-1.3

b. D 2: Formas de vivir en el mundo. Conlleva al desarrollo sociocultural, a las interrelaciones en la ciudadanía global, al arraigo pluricultural y a la construcción de proyectos de vida. Promueve además la responsabilidad personal y social, ligadas a la convivencia, a la vida y a la escogencia de carrera.

c. D 3: Formas de relacionarse con otras personas. Desarrollo de puentes mediante comunicación y colaboración

d. D 4: Herramientas para integrarse al mundo. Apropiación de tecnologías digitales y manejo de la información

Propone la integración de las cuatro dimensiones y sus habilidades en el desarrollo educativo, al presentar una tabla que cruza habilidades con formas de pensar, formas de vivir, formas de relacionarse y herramientas para integrarse. Además, como indicador asume el desarrollo de capacidades como sustento principal e incluye un perfil de salida para una nueva ciudadanía, según cada dimensión, así como las habilidades educativas a desarrollar relacionadas con el enfoque de sostenibilidad.

En el documento citado se entiende la educación como un proceso integral a lo largo de la vida, "que propicia el desarrollo de la sociedad", el desarrollo pleno de las personas, que "recreen su identidad" y que "enriquezcan su visión de mundo" para promover el fortalecimiento de la paz. Busca además la transformación estructural del sistema educativo: un cambio en las formas de educar y de asumir los diversos abordajes pedagógicos. Propone la participación de la ciudadanía activa y comprometida, a fin de lograr cambios mediante el diálogo, la concertación y el trabajo colectivo.

Retoma las cinco líneas de trabajo del MEP en el marco de una educación para la vida, que fomente la creatividad y la innovación y que potencie el desarrollo humano con equidad y sostenibilidad en los centros educativos de calidad: problemática socioambiental global, los objetivos del desarrollo sostenible (ODS), el modelo de educación para el desarrollo sostenible, el enfoque de la sostenibilidad y el currículo por habilidades, entendido como mediación pedagógica para construir conocimientos.

Asume el abordaje pedagógico y la formación humanística y tecnológica con el fin de procurar la autonomía personal a través del desarrollo de procesos educativos interactivos centrados en el estudiantado. Replantea los ambientes de aprendizaje (físicos y virtuales) para la promoción del desarrollo sostenible. 
Revista Universidad en DiÁlogo • Vol. 11, N. ${ }^{\circ}$ 1, Enero-Junio, 2021 • 61-102

ISSN 2215-2849 • EISSN: 2215-4752

URL: http://www.revistas.una.ac.cr/index.php/dialogo/index CorReo ElECTRÓNICO: universidadendialogo@una.cr DOI: http://doi.org/10.15359/udre.11-1.3

Promulga además la mediación pedagógica basada en teorías educativas que centran su interés en el estudiantado y en la construcción de conocimientos, siendo la persona docente facilitadora de aprendizajes significativos y contextualizados para el y la estudiante. Fomenta la construcción de ambientes de aprendizaje diversos, tanto presenciales como virtuales, tendientes a fortalecer la creatividad, el asombro y la interacción lúdica, comunitaria y colectiva, y que propicien el desarrollo de las nuevas habilidades para el siglo XXI, así como la incorporación de tecnologías móviles. La evaluación formativa se constituye como un proceso sistemático de revisión integrado a la construcción de conocimientos, con la idea de contribuir a generar y fortalecer el propio aprendizaje.

La evaluación transformadora se fundamenta en la autorrevisión continua, con el fin de que cada quien identifique sus propias lagunas conceptuales, por tanto, aprovecha los errores como parte del aprendizaje. Se asume como una forma de identificar la complejidad de retos que implican los nuevos aprendizajes e involucra una evaluación continua como parte inherente de la mediación pedagógica.

Como parte de este andamiaje fundacional, a finales del año 2016 el Consejo Superior de Educación propició la elaboración de una nueva política educativa, asumiendo de manera prioritaria que la educación costarricense se halla inmersa en una nueva etapa de desarrollo.

La nueva política curricular y los cambios en los planes de estudio justifican tal decisión, ya que se han venido gestando procesos de renovación y cambio de manera colectiva e innovadora. Dos documentos constituyen sus antecedentes más cercanos: la política educativa del año 1994, titulada Hacia el Siglo XXI, y el documento El centro educativo de calidad como eje de la educación costarricense del año 2008.

En lo referente a su marco filosófico y conceptual, podemos señalar cuatro vertientes fundamentales:

\section{El paradigma de la complejidad:}

Plantea que el ser humano es un ser autoorganizado y autorreferente, es decir que tiene conciencia de sí y de su entorno. Su existencia cobra sentido dentro de un ecosistema natural social-familiar y como parte de la sociedad. En cuanto a la adquisición de conocimiento, este paradigma toma en cuenta que las personas estudiantes se desarrollan en un ecosistema bionatural (que se refiere al carácter biológico del conocimiento, en cuanto a formas cerebrales y modos de aprendizaje) (Política Educativa, 2016, p. 9). 


\section{Humanismo:}

Se orienta hacia el crecimiento personal y, por lo tanto, aprecia la experiencia de la persona estudiante, incluyendo sus aspectos emocionales. Cada persona se considera responsable de su vida y de su autorrealización. La educación, en consecuencia, está centrada en la persona, de manera que sea ella misma la evaluadora y guía de su propia experiencia, a través del significado que adquiere su proceso de aprendizaje. Cada persona es única, diferente, con iniciativa, con necesidades personales de crecer, con potencialidad para desarrollar actividades y solucionar problemas creativamente (Política Educativa, 2016, p. 9).

\section{Constructivismo social:}

El propósito se cumple cuando se considera el aprendizaje en el contexto de una sociedad, tomando en cuenta las experiencias previas y las estructuras mentales de la persona que participa en los procesos de construcción de los saberes (Política Educativa, 2016, p. 10).

\section{Racionalismo:}

“...que se sustenta en la razón y en las verdades objetivas como principios para el desarrollo de conocimiento válido..." (Política Educativa, 2016, p. 11).

La nueva política educativa asume la calidad como principio nuclear que se articula con otros, tales como la inclusión, la equidad, el respeto a la diversidad, la multiculturalidad y la pluriculturalidad, la igualdad de género, la sostenibilidad, la resiliencia y la solidaridad. Señala como metas educativas la formación humana para la vida y el desarrollo de habilidades, destrezas, competencias, actitudes y valores. Sus ejes se orientan en los siguientes postulados:

a. La educación centrada en la persona estudiante: “...potenciar el desarrollo integral de la persona estudiante...” (p. 11).

b. La educación basada en los derechos humanos y los deberes ciudadanos: Conlleva asumir compromisos para hacer efectivos esos mismos derechos y deberes, mediante la participación de la ciudadanía activa orientada a los cambios que se desean realizar (Política Educativa, 2016, p. 11). 
c. La educación para el desarrollo sostenible: “...empoderamiento de las personas a fin de que tomen decisiones informadas, asuman la responsabilidad de sus acciones individuales y de su incidencia en la colectividad actual y futura...que contribuyan al desarrollo de sociedades con integridad ambiental, viabilidad económica y justicia social para las presentes y futuras generaciones..." (Política Educativa, 2016, p. 11).

d. La ciudadanía planetaria con identidad nacional: Significa fortalecer la toma de conciencia de la conexión e interacción inmediata que existe entre personas y ambientes, memoria histórica, incidencia de acciones locales en las globales y viceversa.

e. La ciudadanía digital con equidad social: Se refiere al desarrollo de un conjunto de prácticas, orientadas a la disminución de la brecha social y digital mediante el uso y aprovechamiento de las tecnologías digitales (Política Educativa, 2016, p. 12).

\section{La evaluación transformadora para la toma de decisiones:}

Los sistemas de evaluación, tanto en el ámbito curricular como en la implementación de la presente política, se orientarán hacia la revisión continua, con el fin de identificar los aspectos por mejorar, reconocer y hacer frente de manera positiva ante la complejidad de los retos de la contemporaneidad (Política Educativa, 2016, p. 12).

En lo referente a las orientaciones para una nueva realidad, destacan los siguientes siete planteamientos:

1. La educación centrada en la persona estudiante y su proceso de aprendizaje

2. La educación como un proceso a lo largo de la vida

3. La ciudadanía del siglo XXI

4. Ciudadanía digital e innovación

5. Espacios para el vínculo, la convivencia y el desarrollo del potencial de cada persona en el centro educativo

6. Desarrollo progresivo de habilidades y competencias del siglo XXI

7. Evaluación de los procesos educativos 
En relación con la transformación profesional, se asume que la persona docente es clave en los procesos de aprendizaje en el marco de la formación permanente. Se destaca su figura como persona mediadora de procesos complejos de aula, en el marco de la tolerancia hacia la diversidad, en un ambiente libre de acoso, violencia y discriminación.

Con las universidades formadoras se generará un trabajo conjunto y el intercambio de expectativas y necesidades con el MEP. Además, se intentará fortalecer los procesos de selección de las personas que ingresan. Se propiciará también la autoevaluación docente, la cooperación entre escuelas y colegios y las redes entre profesionales, así como el aprovechamiento de las buenas prácticas.

Esta política educativa establece una educación centrada en el estudiantado y su proceso de aprendizaje y se encuentra articulada bajo una visión de equidad, igualdad de género, diversidad, multiculturalidad, pluriculturalidad, respeto, sostenibilidad, resiliencia y solidaridad, así como el fortalecimiento de destrezas, competencias, actitudes y valores.

Este nuevo abordaje y perspectiva se complementa con los nuevos programas de educación que están orientados hacia el desarrollo de habilidades y competencias necesarias para desenvolverse en pleno siglo XXI. Mediante el uso de diversas estrategias de mediación se propiciarán espacios inclusivos que permitan eliminar barreras de aprendizaje para aquellos y aquellas estudiantes en condiciones educativas menos favorables. Esto con el fin de ofrecer un ambiente educativo que garantice igualdad de oportunidades, según las necesidades y capacidades de cada una de las personas estudiantes.

Asimismo, debe brindarse especial atención a los y las estudiantes con alta dotación y talentos, de manera que se les estimule y se garantice un óptimo desarrollo de sus capacidades y competencias, así como la promoción de un aprendizaje basado en evidencias y los procesos de autoevaluación de los aprendizajes por parte del estudiantado.

En tal sentido se afirma:

Se implementarán estrategias educativas que refuercen valores y logren el desarrollo de competencias, estimulen la curiosidad intelectual, la indagación, el razonamiento riguroso y la cultura científica en la persona estudiante, además de promover el uso educativo de las tecnologías digitales. (Consejo Superior de Educación, p. 19) 
Revista Universidad en DiÁlogo • Vol. 11, N. ${ }^{\circ}$ 1, Enero-Junio, 2021 • 61-102

ISSN 2215-2849 • EISSN: 2215-4752

URL: http://www.revistas.una.ac.cr/index.php/dialogo/index CoRreo ElECTRÓNICO: universidadendialogo@una.cr DOI: http://doi.org/10.15359/udre.11-1.3

A partir del año 2005 y en el marco de la construcción del Acuerdo Nacional sobre Educación, gestionado por el Consejo Superior de Educación y el Ministerio de Educación Pública de Costa Rica, se convoca a una construcción colectiva con el objetivo de avanzar hacia la definición de una Política de Estado con respecto a la educación nacional.

Es en este sentido que se conforman comisiones que comienzan a trabajar en temas como calidad, pertinencia y equidad en la educación; evaluación de la educación costarricense; gestión eficiente; recursos humanos del sistema educativo; empoderamiento de la comunidad educativa; y el marco legal y regulatorio de la educación costarricense.

En función de los resultados obtenidos en el año 2008, se redactó un documento de consenso que plasma las ideas-fuerza que servirían como ejes orientadores del proceso iniciado sobre los centros educativos como eje de la calidad de la educación nacional. Según el citado documento, la intencionalidad es clara: la consolidación y crecimiento de los centros educativos de calidad para garantizar la excelencia en educación a fin de acceder a un tipo de formación que les permita tener una vida individual y socialmente buena, plena y trascendente. En síntesis, el logro de una educación de calidad como un derecho de todas y todos.

El centro educativo de calidad deberá contar, según estipula el documento, con una identidad institucional más rica, con mayor autonomía relativa, con capacidad de decisión y con una participación más amplia de la comunidad educativa (estudiantes, madres y padres de familia, personal y miembros de la comunidad local).

Para la consecución de tal fin se presentan doce ideas-fuerza que pautan la puesta en práctica de un currículo básico y general, con las particularidades propias de cada institución educativa y entendiendo a la educación como un derecho humano fundamental, con principios de relevancia, pertinencia, inclusividad, integralidad y equidad.

Tal como lo especifica el documento analizado, su divisa se centra en la idea de que a la calidad de la educación solo se llega por la calidad del centro educativo. Resumiendo, la idea-fuerza central que se promueve mediante este documento es "lograr que todos y cada uno de los centros educativos del país sean centros educativos de calidad" (Garnier, 2008, p. 3).

Por medio de las 15 orientaciones estratégicas institucionales (2016) del MEP se pretende que exista una mejora sustancial de la calidad educativa, a partir de procesos que consideren la diversidad, la inclusión, la innovación en 
la enseñanza y el aprendizaje, la cobertura en enseñanza de segundo idioma, la equidad y los compromisos sociales como aspectos fundamentales para el desarrollo del acto educativo.

Finalmente, se pretende el desarrollo de profesionales y servicios educativos que permitan un mejor y mayor desempeño en la gestión de procesos pedagógicos, con el fin de contribuir al mejoramiento cualitativo de la educación costarricense.

$\mathrm{Al}$ analizar las 15 orientaciones institucionales estratégicas propuestas por el MEP podemos visualizar planteamientos de diferente naturaleza, alcance y aplicabilidad que, en su conjunto, aunque desarticuladas, marcarían los principales desafíos a enfrentar.

Algunas son indudablemente orientaciones más generales que atañen a todo el sistema educativo, tales como la gestión orientada a la calidad, la equidad, el servicio, la eficiencia, la transparencia y la planificación, como compromisos superiores con la comunidad educativa nacional; la lucha contra la exclusión y el abandono escolar; y la evaluación de la calidad que sustente la toma de decisiones para mejorar los procesos de enseñanza y aprendizaje.

Otras, como un segundo bloque, sin embargo, parecen apuntar a mejorar las condiciones del centro educativo, como la promoción de este como espacio de oportunidad, en condiciones de equidad, pertinencia y calidad, para las y los estudiantes, así como la renovación del sistema de gestión y desarrollo de infraestructura educativa para atender de manera oportuna las demandas, en particular, en zonas de menor desarrollo.

Un tercer bloque intenta el mejoramiento cualitativo de las prácticas de enseñanza y aprendizaje y apunta a la ampliación de la cobertura de la enseñanza de un segundo idioma; también apuesta a la innovación en los procesos de enseñanza y aprendizaje a partir de la incorporación de tecnologías móviles y se complementa con la tendencia de continuar con la actualización de los programas de estudio e incorporar la educación para el desarrollo sostenible.

\section{Ruta metodológica}

De forma específica, la metodología se decanta por el abordaje hermenéutico pedagógico crítico en la medida en que la investigación comprende, interpreta y valora contextos, textos y discursos, configurando sentidos y significados mediante procesos de diálogo autorreflexivo y metacognitivo, con el fin de enriquecer teóricamente los análisis propuestos. 
Rescataremos la voz de los y las docentes mediante la sistematización de treinta cuestionarios aplicados a docentes en servicio, que han servido como pretexto formativo para la revisión del Plan de Estudios de Español para I y II Ciclos de la Educación General Básica, con especial énfasis en las relaciones pedagógicas y didácticas de la enseñanza, en el marco del curso teórico-práctico Introducción al Currículo, del último nivel de bachillerato de la carrera de Pedagogía con Énfasis en I y II Ciclos, de la División de Educación Básica del Centro de Investigación y Docencia (CIDE) de la Universidad Nacional (UNA), en concordancia con la intencionalidad de curricularizar las prácticas extensivas y la interacción situada, para que colaboren en los procesos formativos y curriculares de la enseñanza, del aprendizaje y de la investigación, al ligar y confrontar posturas teóricas versus realidades del aula escolar.

Las y los estudiantes de IV nivel de la carrera Pedagogía con Énfasis en I y II Ciclos entrevistaron a la docente guía de la sección y escuela donde realizaban su práctica. En total se entrevistaron treinta docentes de primaria de diversos centros educativos a lo largo del país, principalmente de las provincias de San José, Alajuela y Heredia.

El instrumento de entrevista dirigido a docentes contiene las siguientes preguntas generales:

1. ¿Cómo considera que debe hacerse la planificación de actividades para un mejor abordaje o puesta en marcha del nuevo programa de Español?

2. ¿Cómo identifica usted las necesidades de aprendizaje en las habilidades lingüísticas y comunicativas de los y las estudiantes?

3. ¿Cómo promueve en sus estudiantes un aprendizaje significativo en relación con los contenidos que el programa propone?

4. ¿Cuáles estrategias de mediación pedagógica utiliza para fortalecer las habilidades lingüísticas y comunicativas que propone el programa de español?

5. ¿Agrega actividades adicionales a las que propone el programa? Cite ejemplos de buenas prácticas.

6. ¿Cuáles estrategias utiliza para la promoción y el fomento de los hábitos de lectoescritura? 
7. ¿Cómo considera usted que se puede asumir desde el programa de Español el enfoque de la educación inclusiva?

8. ¿Cuáles estrategias se están utilizando para articular curricularmente el programa de Español con las asignaturas básicas de Matemática, Estudios Sociales y Ciencias?

\section{Sistematización de los resultados de los cuestionarios}

Analizamos los principales hallazgos encontrados, rescatando la voz de las y los docentes, sus opiniones, creencias y certezas, es decir, sus saberes y sentires. A continuación, especificaremos algunos datos personales y laborales de las personas docentes entrevistadas que contextualizan sus respuestas.

Con respecto a los años de experiencia de las personas docentes entrevistadas, estos van desde los cuatro años hasta los treinta y ocho años de experiencia. El siguiente gráfico muestra con más detalle dicha información:

Figura 1

Años de experiencia laboral en docencia

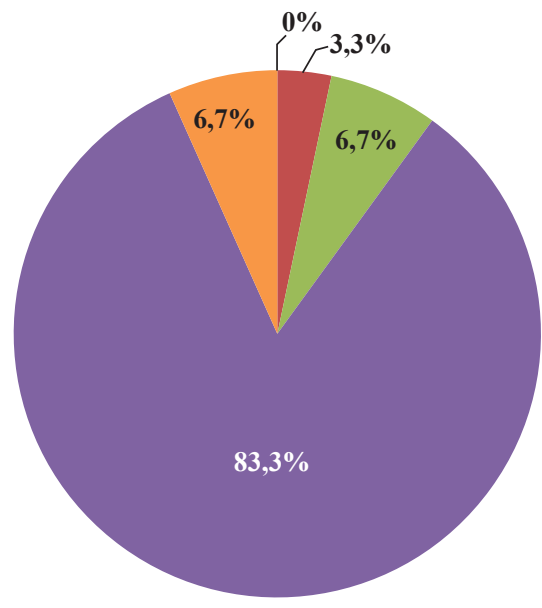

Menos de 1 año

Entre 1 y 5 años

Entre 5 y 10 años

Más de 10 años

No aparece

Nota. Elaboración propia

Por lo tanto, hay $0 \%$ de personas docentes entrevistadas con menos de un año de experiencia, un 3,3\% equivalente a una persona docente ubicada en la categoría "entre uno y 5 años" de experiencia, un $6,7 \%$ correspondiente a un total de dos personas docentes, ubicadas "entre 5 y 10 años" de experiencia, 
y un $83,3 \%$ correspondiente a un total de veinticinco docentes - del total de personas entrevistadas - que poseen más de diez años de experiencia laboral en docencia. Por su parte, el otro $6,7 \%$ equivale a dos personas que no suministraron la cantidad de años de experiencia laboral en docencia.

Asimismo, de las treinta personas docentes entrevistadas hay un 76,7 \% (veintitrés docentes) que proviene de universidades públicas, mientras que otro $20 \%$ (seis docentes) realizó sus estudios en Educación en universidades privadas. Por su parte, un 3,3\% (una persona docente) no suministró dicha información mediante la entrevista. Se presenta el siguiente gráfico para mostrar la información previamente mencionada:

Figura 2

Tipos de universidades de las que provienen los y las docentes

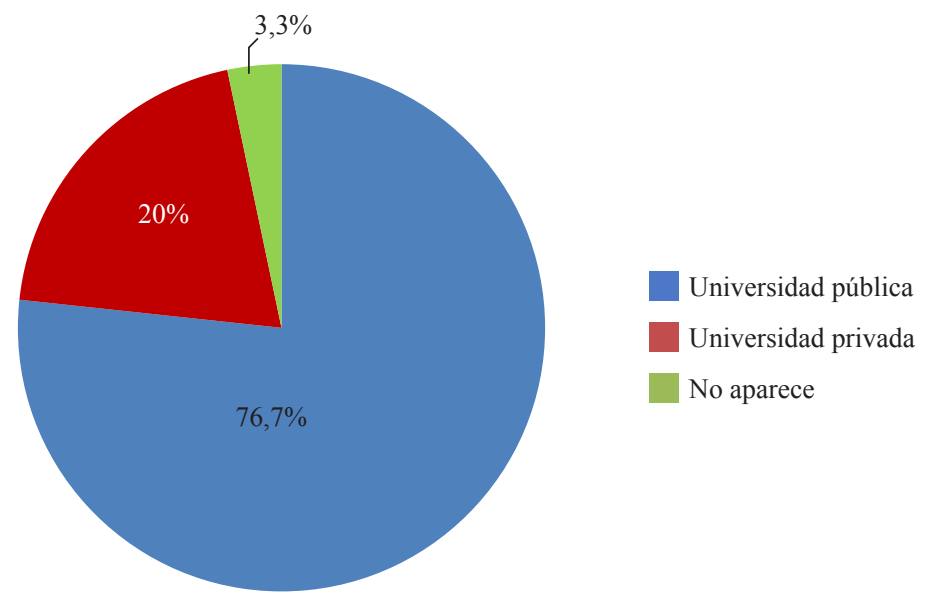

Nota. Elaboración propia

Los últimos grados académicos obtenidos por las personas docentes entrevistadas se ubican entre el bachillerato, la licenciatura y la maestría. Además, la categoría profesional que estas poseen es un PT6, a excepción de una docente que tiene un ET4.

El siguiente gráfico presenta de manera distribuida el porcentaje de los y las docentes según su último grado académico obtenido: 
URL: http://www.revistas.una.ac.cr/index.php/dialogo/index

CORREO ELECTRÓNICO: universidadendialogo@una.cr

DOI: http://doi.org/10.15359/udre.11-1.3

Figura 3

Último grado académico obtenido

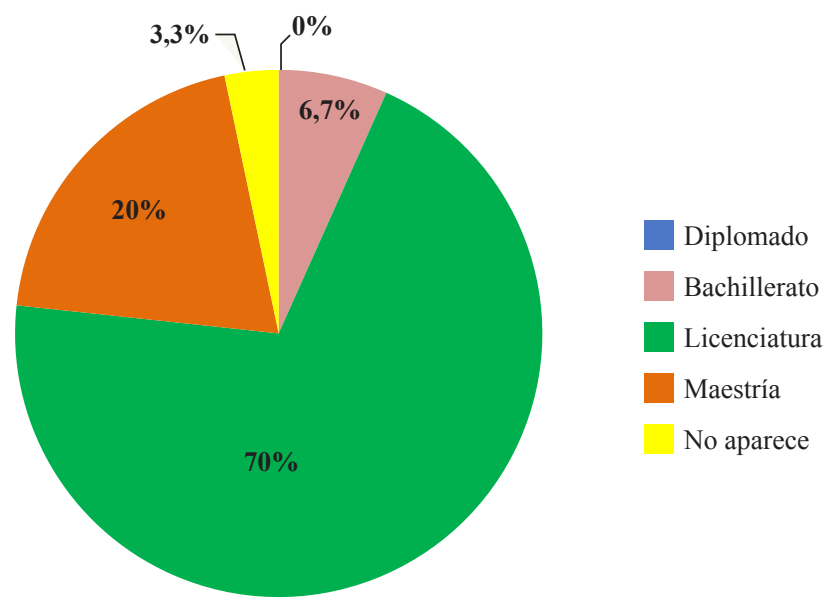

Nota. Elaboración propia

En el gráfico anterior se resalta que un $70 \%$ de las personas docentes entrevistadas (veintiún docentes) posee como último grado académico obtenido la licenciatura. Un $20 \%$ (seis docentes) cuenta con una maestría; un 6,7\% (dos docentes) tiene un grado académico de bachillerato y ninguna de las personas entrevistadas posee como último grado académico obtenido un diplomado. El $3,3 \%$ restante equivale a un docente cuya información sobre su último grado académico obtenido no fue suministrada durante la entrevista.

Las edades de las personas educadoras entrevistadas oscilan entre los veinte y los sesenta años. Se incluye el siguiente gráfico para presentar dicha información de forma más detallada.

De acuerdo con el gráfico 4, un 3,3\% (un docente) de las personas entrevistadas posee "entre 20 y 30 años" de edad, mientras que $26,7 \%$ (ocho docentes) se ubica en la categoría de "mayor de 50 años". Un $60 \%$, equivalente a dieciocho docentes, se ubica en la categoría "entre 30 y 50 años" de edad, por lo cual esta categoría representa a más de la mitad de las personas entrevistadas. El $10 \%$ restante corresponde a un total de tres docentes, cuya información sobre su edad no fue proporcionada durante la entrevista. 
Revista Universidad en DiÁlogo • Vol. 11, N. ${ }^{\circ}$ 1, Enero-Junio, 2021 • 61-102

URL: http://www.revistas.una.ac.cr/index.php/dialogo/index CORREO ELECTRÓNICO: universidadendialogo@una.cr DOI: http://doi.org/10.15359/udre.11-1.3

\section{Figura 4}

Promedio de edades de las personas educadoras entrevistadas

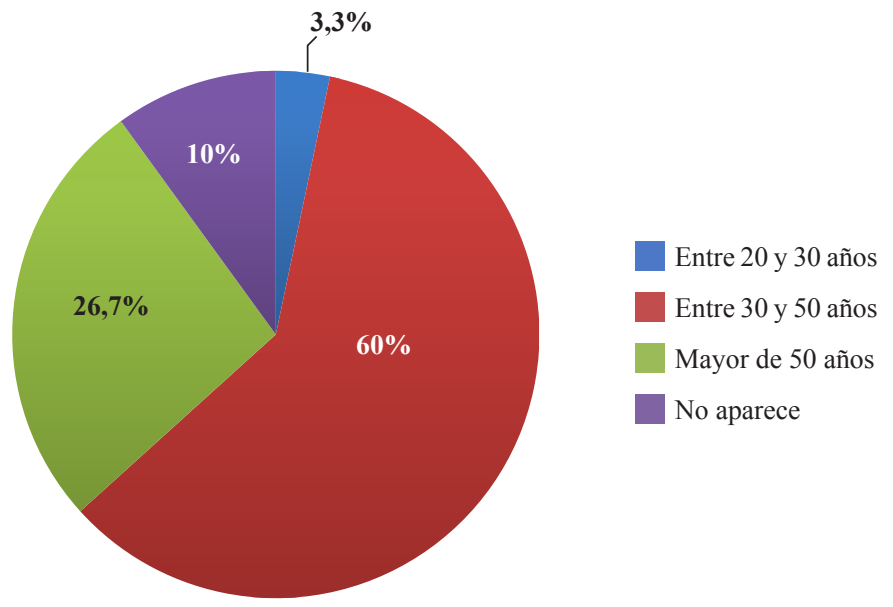

Nota. Elaboración propia

La siguiente información corresponde a la distribución de las personas docentes entrevistadas, según el grado de enseñanza que imparten, para ello se muestran de manera gráfica los datos correspondientes:

Figura 5

Grados de enseñanza que imparten las personas docentes entrevistadas

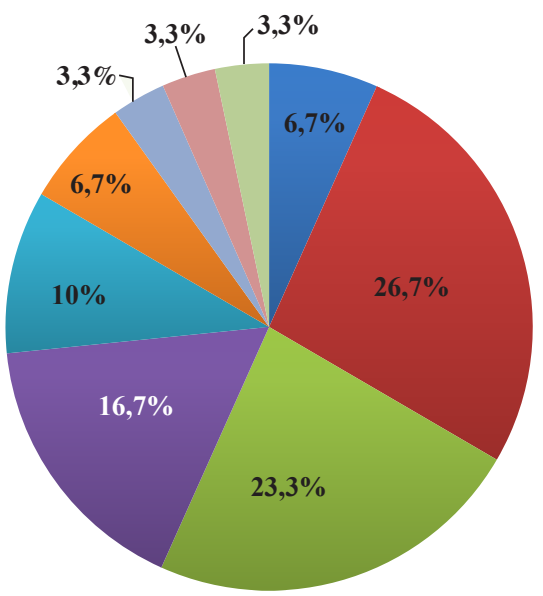

Primer Grado

Segundo Grado

Tercer Grado

Cuarto Grado

Quinto Grado

Sexto Grado

Doble grado

Otro grado de enseñanza

No aparece

Nota. Elaboración propia 
El gráfico anterior muestra que 26,7\% (ocho docentes) imparte segundo grado y 23,3\% (siete docentes) imparte tercer grado. Asimismo, 16,7 \% (cinco docentes) enseña en cuarto grado, $10 \%$ (tres docentes) enseña en quinto grado, $6,7 \%$ (dos docentes) imparte sexto grado y otro 6,7 \% (dos docentes) imparte primer grado. Por su parte, un 3,3\% equivale a un docente que menciona trabajar con personas adultas, otro $3,3 \%$ corresponde a un docente que imparte segundo y cuarto grado y, finalmente, el otro 3,3 \% equivale a un docente cuya información sobre el grado de enseñanza que enseña no fue suministrada durante la entrevista.

De acuerdo con la primera pregunta, podemos señalar, en primer lugar, que las y los docentes conciben la necesidad de que el Ministerio de Educación Pública brinde capacitación sobre las formas de planear, o bien, se proporcione una guía de cómo hacerlo, con el fin de que la planificación de actividades se realice de una manera adecuada. Lo anterior se debe a que el cambio curricular en el Plan de Español ha generado confusiones en docentes sobre la manera de trabajar y organizar lo que se les solicita.

Comentan que la amplitud del programa y la organización de los apartados al momento de realizar la planificación personal genera confusión. A manera de ejemplo, se recalca lo expuesto por algunas personas docentes a partir de sus respuestas: "Como está explicado en el programa, no es fácil de entenderlo y creo que el Ministerio ha fallado en no brindar el apoyo más especializado"; “...el MEP debería presentar una guía más específica para los niveles de cómo ir desarrollando, hasta que los docentes, podamos ir, dominando este enfoque se le está dando, pero como está presentando el programa, no es fácil seguirlo".

Bueno yo pienso que es súper importante que primero que todo, los docentes reciban una capacitación respecto a la forma adecuada de cómo se utiliza el programa, porque definitivamente tiene sus dificultades en el sentido que tiene que adelantarse o atrasarse en las diferentes páginas que este tiene para poder desarrollar adecuadamente lo que se propone (...) y bueno es importante que el docente lo lea y lo entienda para poder desarrollarse uno mismo y mejor potenciar el trabajo de español.

De igual manera, a partir de los comentarios anteriores, se rescata que un punto primordial para la planificación es que la persona docente lea y analice la fundamentación del programa de Español y se informe de lo que este estipula, de manera que al planear el o la docente tenga una visión más amplia de los propósitos del MEP contenidos en el nuevo plan.

A partir de la misma pregunta, algunas personas docentes consideran pertinente que durante el proceso de planificación se tomen en cuenta las características 
Revista Universidad en DiÁlogo • Vol. 11, N. ${ }^{\circ}$ 1, Enero-Junio, 2021 • 61-102

ISSN 2215-2849 • EISSN: 2215-4752

URL: http://www.revistas.una.ac.cr/index.php/dialogo/index CorReo ElECTRÓNICO: universidadendialogo@una.cr DOI: http://doi.org/10.15359/udre.11-1.3

y necesidades del estudiantado, de modo que las estrategias pedagógicas y la metodología utilizadas se ajusten a lo requerido y se brinde un aprendizaje inclusivo, significativo y participativo.

Asimismo, es fundamental que la persona docente realice una contextualización de los contenidos y aborde el plan de estudios de manera que les permita a los y las estudiantes aprender de acuerdo con su entorno, tal como se expresa en la siguiente respuesta:

...el docente tiene que contextualizar todo ese programa para poder tener el abordaje y para que se dé un aprendizaje correcto. Por supuesto hay que tomar en cuenta dichas actividades, contextualizarlas y también ponerles ese toque del maestro, el maestro generalmente tiene muchas estrategias que ha ido recabando con los años y también de las experiencias, de lo vivido, entonces a partir de ahí se va dando esa planificación del programa de estudios.

Asimismo, una docente menciona que las estrategias deben ser “...contextualizadas de acuerdo con las características y necesidades del grupo. Implementar estrategias metodológicas basadas en la observación, la indagación, la elaboración de argumentos, la construcción de significados y el aprendizaje significativo".

Otra docente expresa que "la planificación de las actividades debe hacerse tomando en cuenta las necesidades de los estudiantes que integran el grupo. Hay que conocerlos para poder proponer las actividades y que se ajusten a ellos". También se comparte otro comentario al respecto:

...yo creo que uno primero debe de conocer la población con la que esté trabajando y siempre alistar las actividades a esa población, porque no es lo mismo que yo esté aquí en Heredia dando clases a que yo tenga que ir qué sé yo a Sarapiquí. Es otro grupo, con otras características, tiene que ver la población con la que va a trabajar y adecuar las clases a ellos.

Si bien es cierto que el Plan de Estudios de Español brinda una posible propuesta de enseñanza, la o el docente tiene a su disposición, al momento de planear las actividades, una serie de decisiones que le competen como profesional, que implican considerar la forma en la que se va a estructurar la clase y las dinámicas que aplicará para el proceso de enseñanza.

Algunas personas docentes, a través de sus respuestas, exponen que su experiencia en docencia les permite tomar decisiones sobre cómo organizar la enseñanza y, por ende, la planificación de actividades: "Yo considero que el maestro puede aportar su propia experiencia". 
Los programas del MEP si uno lo analiza yo estoy convencida que uno debe de enseñar con metodología fonética, pero realmente no todos los chicos aprenden con el método fonético. Por metodología uno debe de conocer la comunidad estudiantil que le corresponde a uno para ver cuál es la manera de aprender.

Ahora bien, otro punto recabado a partir de esta pregunta es la necesidad de contemplar en la planificación procesos de lectura y lectoescritura, así como la expresión oral y la expresión escrita, de manera que el estudiantado desarrolle una "capacidad comunicativa" y se aborde uno de los principales enfoques del MEP en esta materia, relacionado con el desarrollo de las competencias comunicativas en los y las discentes como núcleo básico del aprendizaje y del desarrollo, tanto para esta asignatura como para las demás materias académicas:

Bueno es que ahora se está fundamentando más en la lectura. Se parte de la lectura y de ahí está lo que es la gramática aplicada en la lectura entonces si deben de haber más actividades lúdicas y...deben de incluirse, fomentarse en la lectura diaria pero lecturas que sea de acorde a ello de acorde a los... a los gustos para que sea... por llamativo y ello... para que sea más fácil también...más agradable.

Aseguran que las estrategias pedagógicas planeadas deben proponer al estudiantado un aprendizaje atractivo y dinámico en el cual se sienta motivado al momento de aprender y que forme parte del proceso de enseñanza y aprendizaje:

Aunque tengan su libro les aburre trabajar con su libro. Les encanta trabajar en grupos. Les encanta recortar, pegar, entonces cuando yo les digo planeemos qué vamos a hacer de $\mathrm{x}$ tema, eso es lo que ellos proponen siempre. Para mi uno debe, en la medida de lo posible verdad, preguntarles a ellos que les gustaría.

Se destaca también que el abordaje del programa puede considerar la integración de otras disciplinas, de modo que se contemplen diversos saberes que contribuyan al aprendizaje:

Según el programa de español, en la parte de estructura y las actividades, lo que más creo conveniente es lo que dice el programa, tomar en cuenta otras disciplinas como es la música, las actividades físicas y acoplarlo a cada tema, estar claro en el objetivo y contenido de cada tema que se quiera aplicar y ver estrategias que no sean tradicionales, como ver una película y hacer preguntas, algo más interactivo. 
Revista Universidad en DiÁlogo • Vol. 11, N. ${ }^{\circ}$ 1, Enero-Junio, 2021 • 61-102

ISSN 2215-2849 • EISSN: 2215-4752

URL: http://www.revistas.una.ac.cr/index.php/dialogo/index CorReo ElECTRÓNICO: universidadendialogo@una.cr DOI: http://doi.org/10.15359/udre.11-1.3

Por otra parte, algunas personas docentes mencionan que se debe planear de forma mensual, y que, además, aliarse con los y las docentes del mismo nivel y formar equipos docentes constituye una buena estrategia de apoyo. Por ejemplo, una docente menciona:

Bueno yo creo que la planificación se debe hacer en conjunto con las compañeras del nivel de manera que todas puedan aportar ideas y una variedad de actividades que ayuden a los niños para que así sea un abordaje bueno del programa de español.

Finalmente, es importante exponer algunos comentarios surgidos al responder esta pregunta, pues algunas personas docentes señalan que existen diversas limitantes que impiden un adecuado abordaje del plan, entre ellas la carga académica y la resistencia por parte de los y las docentes a aplicar los nuevos programas, ya que organizan sus prácticas educativas utilizando las metodologías y los enfoques tradicionales:

Ahora las maestras que tienen muchísimos años de experiencia y están acostumbradas a trabajar con planes viejos aunque hayan planes nuevos no van a seguir los pasos, aunque hayan recibido la capacitación que recibimos, que fue como una semana, lo he visto, porque no manejan ciertas técnicas...

En este sentido, la siguiente tabla presenta de forma sistematizada los principales datos obtenidos mediante las respuestas de docentes acerca de cómo debe realizarse la planificación de actividades para un mejor abordaje o puesta en marcha del nuevo programa de Español:

Tabla 1

Planificación adecuada para el abordaje del Programa de Español

\begin{tabular}{|l|l|}
\hline \multicolumn{2}{|l|}{ Planificación adecuada para un mejor abordaje del nuevo Programa de Español } \\
\hline $\begin{array}{l}\text { Capacitación docente por parte del MEP para un } \\
\text { adecuado abordaje del programa }\end{array}$ & $\begin{array}{l}\text { Implementación de estrategias pedagógicas que } \\
\text { contemplen la lectura, lectoescritura y la expresión oral. }\end{array}$ \\
\hline $\begin{array}{l}\text { Lectura y análisis de la fundamentación del } \\
\text { Programa de Español por parte del cuerpo } \\
\text { docente previo a la planificación }\end{array}$ & Planeamiento de forma mensual \\
\hline $\begin{array}{l}\text { Ajuste de las temáticas y desarrollo de actividades } \\
\text { pedagógicas de acuerdo con las características y } \\
\text { necesidades de la población estudiantil de su clase }\end{array}$ & $\begin{array}{l}\text { Planeación y coordinación grupal de docentes } \\
\text { que impartan un mismo nivel escolar. }\end{array}$ \\
\hline Contextualización de contenidos & Abordaje de forma creativa \\
\hline $\begin{array}{l}\text { Integración de diversas disciplinas como parte del } \\
\text { abordaje de las temáticas }\end{array}$ & $\begin{array}{l}\text { Fomento de actividades lúdicas, participativas e } \\
\text { inclusivas }\end{array}$ \\
\hline
\end{tabular}

Nota. Elaboración propia 
URL: http://www.revistas.una.ac.cr/index.php/dialogo/index

CORREO ELECTRÓNICO: universidadendialogo@una.cr

DOI: http://doi.org/10.15359/udre.11-1.3

En cuanto a la segunda pregunta: ¿Cómo identifica usted las necesidades de aprendizaje en las habilidades lingüísticas y comunicativas de los y las estudiantes? Se obtienen una variedad de datos que proporcionan información sobre la forma en la que los y las docentes detectan las necesidades del estudiantado.

La respuesta más destacada es que los y las docentes identifican aquellas limitaciones, debilidades o características presentes en los niños y las niñas con respecto a sus habilidades lingüísticas y comunicativas en el trabajo en el aula y a partir de estrategias de lectoescritura y expresión oral, ya sea de forma individual o grupal. Algunas personas docentes lo exponen de la siguiente manera:

Primero que todo hay que hacer una observación de los estudiantes en clase y los mismos recreos, uno determina cómo está un niño de acuerdo a la forma en que se comunica tanto con sus compañeros como con los docentes, además de verificar la forma en que ellos se desenvuelven a la hora de realizar las intervenciones orales en clases...

"Se identifican con lectura oral, exposiciones, lluvia de ideas en general, el trabajo de aula que se realiza constantemente en todas las materias"; "... mediante la práctica con el trabajo cotidiano...uno se va dando cuenta cuáles personas tienen situaciones particulares en las que necesitan más bien apoyo para seguir adelante o más bien necesitan apoyo para desarrollar bien lo que están haciendo"; "principalmente en actividades como conversatorios, trabajos grupales y expresión escrita".

Mencionan además que la aplicación de diagnósticos iniciales, la revisión de expedientes y la atención sobre el estudiantado que asiste a servicios educativos especiales son fuentes indispensables para identificar posibles necesidades presentes en el estudiantado. A continuación, se expone lo obtenido en algunas respuestas de docentes: “....Mediante el diagnóstico en forma permanente, se evidencia las necesidades de aprendizaje...".

El o la docente es responsable de revisar los expedientes, ya que vienen referencias desde preescolar. La gran mayoría tienen terapia, sin embargo los que no han sido identificados, usualmente manifiestan su dificultad durante las clases de español, no solamente por medio del habla, sino, además por medio de la lectura, escritura y escucha, ya que ya no se segregan las habilidades lingüísticas, al contrario, se trabaja la conciencia fonológica en conjunto. 
También señalan lo siguiente:

Para identificar las necesidades de aprendizaje en las habilidades lingüísticas y comunicativas de los estudiantes, uno hace una valoración, un diagnóstico a inicio de año; también tomamos en cuenta aquellos niños que asisten a terapia de lenguaje o con algunos problemas de articulación".

Finalmente, algunas personas docentes recurren a actividades lúdicas o a entrevistas con las madres y los padres del estudiantado, con el fin de conocer u obtener algún dato en particular sobre el desempeño o la competencia comunicativa de los y las estudiantes.

A continuación, se presenta una tabla que reúne los aspectos más destacados de las respuestas de los y las docentes con respecto a la segunda pregunta de la entrevista.

\section{Tabla 2}

Formas de identificar necesidades de aprendizaje para el desarrollo de las habilidades lingüisticas y comunicativas del estudiantado

\begin{tabular}{|ll|}
\hline $\begin{array}{l}\text { Formas de identificar necesidades de aprendizaje para el desarrollo de las habilidades } \\
\text { lingüísticas y comunicativas del estudiantado }\end{array}$ \\
\hline A través del trabajo en el aula & Contacto directo con el estudiantado \\
\hline Diagnósticos previos & $\begin{array}{l}\text { Observación del desempeño en el aula } \\
\text { e interacción del mismo en diversos } \\
\text { espacios y momentos escolares }\end{array}$ \\
\hline Revisión de expedientes del estudiantado & $\begin{array}{l}\text { Según el ritmo de aprendizaje de los } \\
\text { y las estudiantes }\end{array}$ \\
\hline $\begin{array}{l}\text { Presencia de problemas de lenguaje } \\
\text { u otras limitaciones observadas en el } \\
\text { niño o la niña }\end{array}$ & Forma de expresión de los niños y las niñas \\
\hline $\begin{array}{l}\text { Estudiantes asistentes a servicios } \\
\text { educativos especiales }\end{array}$ & Revisión de trabajos del estudiantado \\
\hline $\begin{array}{l}\text { Entrevista con las madres y los padres } \\
\text { de familia }\end{array}$ & Actividades lúdicas \\
\hline
\end{tabular}

Nota. Elaboración propia 
URL: http://www.revistas.una.ac.cr/index.php/dialogo/index

CORREO ELECTRÓNICO: universidadendialogo@una.cr

DOI: http://doi.org/10.15359/udre.11-1.3

En cuanto a la tercera pregunta: ¿Cómo promueve en sus estudiantes un aprendizaje significativo en relación con los contenidos que el programa propone? Los y las docentes conciben principalmente que las diversas actividades que se desarrollan en el aula, de forma grupal o individual y que impliquen la interacción, la creación, la investigación o el desarrollo de situaciones o materiales concretos, son la fuente principal para promover un aprendizaje significativo, pues promueven mayor interés y participación del estudiantado.

A continuación, presentamos algunos fragmentos de las opiniones de docentes al respecto:

Trato de que la materia no sea de una forma memorística, sin embargo sí sé que hay muchos aspectos que hay que aprendérselos de memoria y con la práctica, se le hace significativo. Por ejemplo, un médico tiene que entender y saber las partes del cuerpo, donde son y punto; con la práctica la persona va ir identificándolas y así es como considero yo que puede ir siendo significativo ese aprendizaje.

Otra persona docente indica:

Lo que he descubierto, es que para que a ellos el aprendizaje les sea significativo uno tiene que hacer una actividad que sea importante para ellos, casi siempre esa actividad la intento manejar con algún juego o una actividad manual, para que sea fácil de recordar, es más factible acordarse el día que hicimos una máscara, ellos lo van a recordar, que si les digo el día que vimos los elementos de la comunicación no se van a acordar, entonces con mucha actividad, mucha dinámica, pero con significado, no es hacer una máscara por hacerla, si no que tenga un significado académico.

Diversas actividades que expongan al estudiantado a situaciones reales de aprendizaje, como los espacios de interacción, las creaciones propias, la variedad de producciones escritas, las lecturas acordes con los gustos e intereses de las y los estudiantes, las dramatizaciones, los talleres, entre muchas otras, son formas de promover aprendizajes significativos en la población estudiantil.

Una de las personas entrevistadas señala: "En el caso mío yo lo que trato es buscar videos, de buscar lecturas que van acordes con la edad con los intereses de los niños y las niñas de hacer actividades relacionadas con su contexto sociocultural". 
Revista Universidad en DiÁlogo • Vol. 11, N. ${ }^{\circ}$ 1, Enero-Junio, 2021 • 61-102

ISSN 2215-2849 • EISSN: 2215-4752

URL: http://www.revistas.una.ac.cr/index.php/dialogo/index Correo eleCtrónico: universidadendialogo@una.cr DOI: http://doi.org/10.15359/udre.11-1.3

Otra docente menciona:

En los estudiantes uno lo promueve (el aprendizaje) de acuerdo a diversas actividades, fomentamos mucho la lectura, el amor hacia los libros, diversos juegos, con prácticas de material fotocopiado; también nosotros tratamos de hacer diversas estrategias para que los niños se enamoren de la lectura.

Según lo expuesto anteriormente, el uso de los recursos tecnológicos y el adecuado material didáctico que se utilice en el aula son herramientas educativas que influyen en la participación e interés del estudiantado en su aprendizaje.

De igual manera, los maestros y las maestras consideran necesario partir de las experiencias y los conocimientos previos de los y las estudiantes, de manera que los nuevos conocimientos se conviertan en aprendizajes significativos.

Los siguientes comentarios reflejan los aspectos mencionados previamente: "Pienso que tomando en cuenta las experiencias que el niño tiene, de manera que los aprendizajes sean más reales a él, más conocidos, para así impactar de una forma más significativa"; "bueno yo pienso que es súper importante tomar en cuenta los conocimientos que ellos tienen".

Con la intención de lograr aprendizajes significativos, yo por lo menos creo que la mejor forma es relacionarlo con situaciones de la vida cotidiana, de la vida diaria, entonces digamos hay que buscar ejemplos o compartir experiencias o que los chicos narren alguna experiencia donde se les solicite y sientan la necesidad de utilizar lo que han aprendido en el aula.

Es fundamental que se genere la participación y el interés en el estudiantado a través de las diversas estrategias pedagógicas implementadas por el o la docente, pues constituyen factores indispensables para que los y las estudiantes desarrollen una mayor confianza en su proceso de aprendizaje significativo.

Los y las docentes asumen que deben hacer partícipes a sus estudiantes del desarrollo de la clase, al tomar en cuenta sus gustos, intereses y habilidades. "Precisamente planeando con ellos las clases, organizando los trabajitos que vamos a hacer, solicitándoles el material a tiempo para construir y cuando se trata de temas de español les gusta mucho dramatizar”.

Además, es importante que se desarrollen temáticas actuales frente a las que el estudiantado se sienta interesado o involucrado, a través de diversas estrategias o actividades de aprendizaje. Las actividades se vuelven significativas cuando el estudiantado es capaz de participar y ser parte de la temática en desarrollo. 
URL: http://www.revistas.una.ac.cr/index.php/dialogo/index

CORREO ELECTRÓNICO: universidadendialogo@una.cr

DOI: http://doi.org/10.15359/udre.11-1.3

Seguidamente, se presentan de forma sistematizada los aspectos relevantes obtenidos de la tercera pregunta de la entrevista:

Tabla 3

Promoción de aprendizajes significativos en el estudiantado

\begin{tabular}{|l|l|}
\hline \multicolumn{2}{|c|}{ Promoción de aprendizajes significativos en el estudiantado } \\
\hline $\begin{array}{l}\text { Emplear estrategias pedagógicas } \\
\text { (grupal e individual) llamativas para el } \\
\text { estudiantado }\end{array}$ & $\begin{array}{l}\text { Tomar en cuenta las experiencias y } \\
\text { los aprendizajes previos de los y las } \\
\text { estudiantes }\end{array}$ \\
\hline $\begin{array}{l}\text { Utilizar recursos tecnológicos y diversos } \\
\text { materiales didácticos que promuevan } \\
\text { la participación y el interés del } \\
\text { estudiantado en su aprendizaje. }\end{array}$ & Promover la investigación en el aula \\
\hline $\begin{array}{l}\text { Proveer espacios de interacción } \\
\text { Abordar temáticas de la actualidad para la } \\
\text { participación activa de los y las estudiantes }\end{array}$ & $\begin{array}{l}\text { Permitir al estudiantado el desarrollo de } \\
\text { creaciones propias }\end{array}$ \\
\hline $\begin{array}{l}\text { Exponer al estudiantado a situaciones en estudiantado confianza e } \\
\text { reales de aprendizaje }\end{array}$ & $\begin{array}{l}\text { Considerar los gustos e intereses del } \\
\text { estudiantado }\end{array}$ \\
\hline Involucrar al estudiantado en la planeación de las próximas temáticas \\
\hline
\end{tabular}

Nota. Elaboración propia

En cuanto a la cuarta pregunta: ¿Cuáles estrategias de mediación pedagógica utiliza para fortalecer las habilidades lingüísticas y comunicativas que propone el programa de Español? Un 40 \% considera la lectura diaria como una estrategia fundamental para el fortalecimiento de dichas habilidades, ya sea de forma individual, grupal o guiada, con el fin de fomentar el gusto por la lectura y al mismo tiempo que los y las estudiantes adquieran destrezas fundamentales para su aprendizaje.

Según lo mencionado por los y las docentes, sus estudiantes realizan lecturas de diversos tipos, como cuentos y poesías, entre otros, algunos escogidos por estudiantes y otros facilitados o sugeridos por el o la docente. Asimismo, estas estrategias les permiten a los y las docentes realizar una serie de actividades "en cadena", que orienten al estudiantado a la producción oral y escrita, con el fin de mejorar su competencia comunicativa. 
Revista Universidad en DiÁlogo • Vol. 11, N. ${ }^{\circ}$ 1, Enero-Junio, 2021 • 61-102

ISSN 2215-2849 • EISSN: 2215-4752

URL: http://www.revistas.una.ac.cr/index.php/dialogo/index CoRreo ElECTRÓNICO: universidadendialogo@una.cr DOI: http://doi.org/10.15359/udre.11-1.3

Se exponen a continuación algunos comentarios de los y las docentes:

Yo trato de utilizar siempre mucha lectura y que ellos puedan desenvolverse bien a la hora de realizar las pausas correspondientes y para que entiendan perfectamente el mensaje, yo pienso que aquí lo más importante es utilizar la lectura para poder aplicar una correcta compresión de lectura y comprender el mensaje que a nosotros nos pueden dar...

Les solicité una noticia buena, y se los recalqué, en el ámbito de la medicina, el arte, la música, el deporte, educación, salud. No era permitido sucesos en religión o política. Donde ellos tuvieran que buscar por semana una noticia de estas, la leyeran y le escribieran un comentario, un comentario donde expresen la opinión. No era copiar la noticia. No es tanto contarla sino es comentarla y darme su punto de vista.

En Español lo más importante es partir con una lectura, entonces a partir de una lectura se comienzan a sacar las palabras, sílabas, sustantivos, lo que sea que se requiera, pero a partir de una lectura, que ellos vean primero la lectura y luego que vayan sacando lo que se necesita individualmente.

Por otra parte, el otro $60 \%$ de respuestas obtenidas a través de la entrevista corresponde a una diversidad de estrategias aplicadas por los y las docentes, en las cuales se recalca en varias ocasiones la comprensión de lecturas, las narraciones de historias, anécdotas u otras situaciones por parte del estudiantado, así como las exposiciones de variados temas, tanto escogidos por los y las estudiantes como sugeridos por la persona docente, y la producción de textos u oraciones.

A partir de dichas estrategias, los y las docentes buscan una participación activa del estudiantado, con el fin de que ponga en práctica los conocimientos previos y los adquiridos en el momento de la enseñanza, para estimular y fortalecer las competencias lingüísticas y comunicativas del estudiantado.

\section{Figura 6}

Estrategias utilizadas

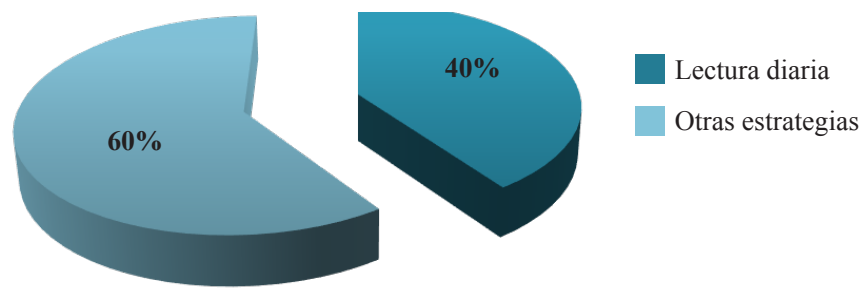

Nota. Elaboración propia 
URL: http://www.revistas.una.ac.cr/index.php/dialogo/index

CORREO ELECTRÓNICO: universidadendialogo@una.cr

DOI: http://doi.org/10.15359/udre.11-1.3

La figura anterior muestra el porcentaje obtenido de las treinta personas entrevistadas que utilizan la lectura diaria como una de las estrategias fundamentales para el fortalecimiento de las competencias lingüísticas y comunicativas. El 60 \% expone una variedad de estrategias tanto de trabajo estudiantil individual como grupal. La siguiente tabla reúne las demás estrategias empleadas por los y las docentes:

\section{Tabla 4}

Estrategias de mediación pedagógica para fortalecer las habilidades lingüisticas y comunicativas que propone el programa de Español

Estrategias de mediación pedagógica para fortalecer las habilidades lingüísticas y comunicativas que propone el programa de Español

\begin{tabular}{ll}
\hline Mimo & Diversas actividades lúdicas, por ejemplo el juego \\
\hline Producción oral & Empleo de títeres \\
\hline $\begin{array}{l}\text { Producción escrita (cuentos, } \\
\text { poesías, etc.) }\end{array}$ & Dramatizaciones \\
\hline Canciones & Narraciones orales \\
\hline Mesas redondas & Exposiciones \\
\hline Conversatorios & Obras de teatro \\
\hline $\begin{array}{l}\text { Comprensión de lectura } \\
\text { (literal e inferencial) }\end{array}$ & Visitas a la biblioteca \\
\hline Lluvia de ideas & Construcción de nuevo vocabulario \\
\hline Trabajo grupal e individual & Transcripción de lecturas \\
\hline $\begin{array}{l}\text { Fomento de la lectura } \\
\text { (la más utilizada) }\end{array}$ & Espacios de argumentación \\
\hline Expresión corporal & Escucha de cuentos y poemas \\
\hline
\end{tabular}

Nota. Elaboración propia

También es importante comentar que los y las docentes utilizan una variedad de materiales que les permiten desarrollar las estrategias mencionadas previamente. Entre estos se encuentran:

- Dibujos

- Imágenes

- Teatrinos

- Disfraces 
- Producciones como adivinanzas, trabalenguas, chistes y poemas

- "Caja viajera de lectura" (mencionado por un docente)

- Rincón de lectura

- Títeres

- Variedad de materiales llamativos

A partir de la pregunta número cinco: ¿Agrega actividades adicionales a las que propone el programa? Se obtiene lo siguiente:

- Un 93,3\% de las personas docentes comenta que sí agregan actividades adicionales a las que propone el programa de Español, debido a diversas razones; una de ellas es que las actividades propuestas en el plan no se adaptan a los intereses, las características o las necesidades de la población. Otra razón es que los y las docentes buscan otras actividades que motiven más al estudiantado en su proceso de aprendizaje y también les permita una mejor comprensión de la temática.

- Asimismo, algunas personas docentes no se sienten a gusto con algunas de las estrategias que propone el programa, por lo que consideran oportuno realizar algunas modificaciones o implementar nuevas propuestas.

A continuación, exponemos algunos comentarios de los y las docentes respecto a la pregunta señalada: "Sí, el programa presenta actividades que no siempre coinciden con las diferencias individuales a atender en el aula o el nivel que el docente imparte, desde ahí hay que partir para planear actividades que contemplen los conocimientos previos".

Claro este siempre se va a agregar actividades, el programa te propone 4-3 actividades y a veces ninguna de esas se adapta con su población, bueno en los primeros grados es muy importante trabajar todo lo que sean bingos, loterías toda que yo juego mucho, juego mucho juego, a los niños les encanta jugar y aunque se diga que hay que evitar la competencia, que estamos intentando construir una cultura de paz, a los niños les encanta la premiación, ya sea que todos salgan premiados y tienes 27 , tenés que premiar a los 27 , pero es algo que los motiva muchísimo al juego, hay que realizar muchos juegos en las primeras edades.

Otra persona señala:

Sí, es importante, el educador nunca termina de investigar ni de saberlo todo, siempre se aprende, los estudiantes le enseñan, entonces es importante, aparte de las actividades que tiene el programa ir creando actividades donde los niños adquieren 
aprendizaje, como he dicho anteriormente, muchas actividades donde utilicen la lógica, donde se desenvuelvan, donde logren manipular, para un aprendizaje mejor, buscar no solo centrarse en un libro o documento, sino buscar y buscar, a veces los alumnos le dan la pauta a uno para que de tal actividad uno saca conclusiones y puede desarrollar más actividades, eso es importante, el niño le da la pauta a uno.

Por otra parte, un 3,33\% corresponde a una de las treinta personas docentes entrevistadas, que expresó que no agrega actividades adicionales a las que propone el programa: "No. Realizo lo que el programa indica y en ocasiones se modifica por el grupo porque la reacción del mismo es diferente todos los días, o no hay actividades de la escuela que interrumpen la dinámica".

Asimismo, el otro 3,33\% corresponde a una docente que mencionó que en ocasiones agrega actividades adicionales:

A veces sí, pero en la mayoría de ocasiones no porque el programa se hace muy amplio entonces uno necesita como aterrizar un poquito más en lo que el niño necesita, yo lo que practico mucho con ellos es la atención individual para ver cuánto realmente está el niño avanzando en el proceso de lectoescritura.

El siguiente gráfico expone los datos proporcionados previamente:

Figura 7

Uso de actividades adicionales a las que propone el programa de Español

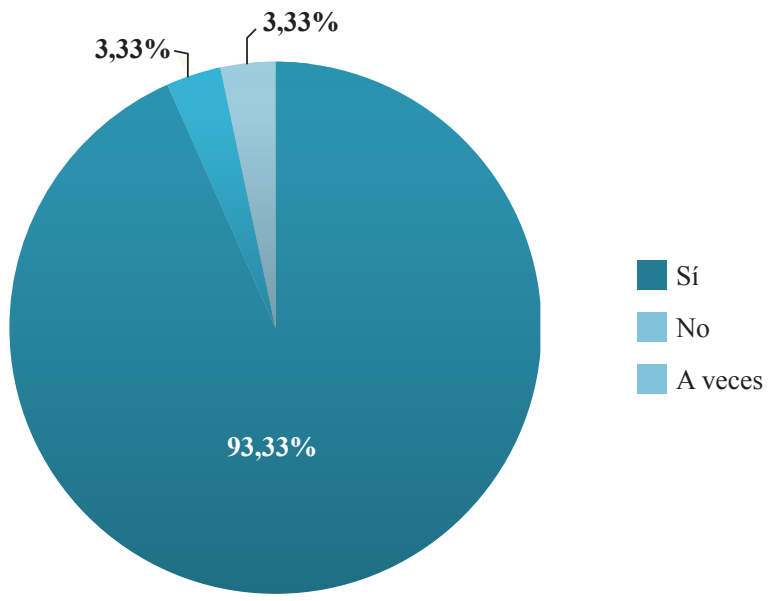

Nota. Elaboración propia 
Revista Universidad en DiÁlogo • Vol. 11, N. ${ }^{\circ}$ 1, Enero-Junio, 2021 • 61-102

ISSN 2215-2849 • EISSN: 2215-4752

URL: http://www.revistas.una.ac.cr/index.php/dialogo/index Correo ElECTRÓNICO: universidadendialogo@una.cr DOI: http://doi.org/10.15359/udre.11-1.3

Con respecto a las "buenas prácticas" mencionadas por los y las docentes, en esta misma pregunta se obtiene la siguiente información:

Tabla 5

Ejemplos de buenas prácticas

\begin{tabular}{|c|c|c|c|}
\hline \multicolumn{4}{|c|}{ Ejemplos de buenas prácticas } \\
\hline $\begin{array}{l}\text { Implementar variedad } \\
\text { de juegos }\end{array}$ & $\begin{array}{l}\text { Realizar } \\
\text { dramatizaciones }\end{array}$ & $\begin{array}{l}\text { Escuchar canciones o } \\
\text { cuentos }\end{array}$ & Realizar máscaras \\
\hline $\begin{array}{l}\text { Usar la pizarra como } \\
\text { medio de participación } \\
\text { del estudiantado }\end{array}$ & Usar libros de texto & $\begin{array}{l}\text { Desarrollar actividades } \\
\text { de lógica }\end{array}$ & $\begin{array}{l}\text { Creación de poesías o } \\
\text { canciones }\end{array}$ \\
\hline Observar videos & $\begin{array}{l}\text { Completar sopas de } \\
\text { letras }\end{array}$ & $\begin{array}{l}\text { Visitar otros lugares } \\
\text { fuera de la escuela }\end{array}$ & $\begin{array}{l}\text { Utilizar una caja con } \\
\text { preguntas } \\
\text { (La cajita del saber) }\end{array}$ \\
\hline Crear lluvias de ideas & $\begin{array}{l}\text { Buscar palabras en el } \\
\text { diccionario }\end{array}$ & Construir álbumes & Promover la imaginación \\
\hline $\begin{array}{l}\text { Usar títeres, revistas, } \\
\text { bingos, música, canciones }\end{array}$ & Ruletas & Competencias o talleres & \multirow{3}{*}{$\begin{array}{l}\text { *Atención } \\
\text { individualizada }\end{array}$} \\
\hline $\begin{array}{l}\text { Construir maquetas y } \\
\text { realizar dibujos y carteles }\end{array}$ & $\begin{array}{l}\text { Recortar palabras del } \\
\text { periódico y clasificarlas }\end{array}$ & $\begin{array}{l}\text { Organizar campañas } \\
\text { comunicativas }\end{array}$ & \\
\hline Realizar crucigramas & \multicolumn{2}{|c|}{$\begin{array}{l}\text { Elaborar esquemas, mapas conceptuales y llaveros } \\
\text { pictóricos }\end{array}$} & \\
\hline
\end{tabular}

Nota. Elaboración propia

Con respecto a la pregunta seis: ¿Cuáles estrategias utiliza para la promoción y fomento de los hábitos de lectoescritura? De acuerdo con los datos registrados en las entrevistas, algunas estrategias se destacan como las más utilizadas, debido a que estas fueron mencionadas por la mayoría de los y las docentes.

La lectura es la principal estrategia utilizada por las personas docentes para la promoción de la lectoescritura, de manera que cumplen con los veinte minutos de lectura diaria estipulados en el programa de Español del MEP. A partir de esta estrategia algunas personas docentes emplean variedad de dispositivos para estimular la lectoescritura, por ejemplo, a partir de un cuento o de otra obra literaria leída, el estudiantado realiza una comprensión de lectura, ya sea de forma grupal o individual. Asimismo, otras personas entrevistadas propician conversatorios donde se comparte sobre lo leído.

Otra forma de promover hábitos de lectoescritura es a través de la creación propia de cuentos, poesías u otras obras literarias por parte del estudiantado. 
URL: http://www.revistas.una.ac.cr/index.php/dialogo/index

CORREO ELECTRÓNICO: universidadendialogo@una.cr

DOI: http://doi.org/10.15359/udre.11-1.3

Según lo expresado por docentes, la motivación hacia el estudiantado es un factor principal durante el proceso de promoción de dichos hábitos. Algunos comentarios de los y las docentes ante esta pregunta se presentan a continuación:

Los chicos saben que una vez a la semana tienen que hacer una copia de caligrafía, del tema que ellos consideren, eso les agrada mucho porque yo cada semana que me lo entregan les escribo un mensaje positivo sobre la copia y hago las correcciones correspondientes de acuerdo a la situación de cada uno, así también se hacen lecturas diarias, cada vez que tenemos la posibilidad para poder fomentar en ellos la lectoescritura y comprensión, que es tan importante para poder comprender cada texto que leemos en la vida.

Otra persona entrevistada indica:

Realizamos siempre una lectura conjunta dirigida por la docente. Tenemos también en el aula un rincón literario y se promueve también en espacios en donde los niños pueden llevar sus propios libros y también llevar una lectura personas y con las actividades de comprensión lectora.

Por último, una persona expresa: "La creación de sus propios textos, los estudiantes disfrutan de contar sus vivencias o expresar los conocimientos que tienen, además de compartirlos con el grupo exponiéndolos".

Otras de las estrategias utilizadas por docentes se presentan en la siguiente tabla:

Tabla 6

Estrategias para la promoción y el fomento de hábitos de lectura

\begin{tabular}{|l|l|l|}
\hline Estrategias para la promoción y el fomento de hábitos de lectura \\
\hline Dictados & $\begin{array}{l}\text { Interpretación de las lecturas a } \\
\text { través de dramatizaciones o música }\end{array}$ & Observación de obras de teatro \\
\hline Caligrafía & Visitas a la biblioteca & $\begin{array}{l}\text { Recortar letras y formar } \\
\text { palabras con ellas }\end{array}$ \\
\hline Lectura diaria & Utilización del Rincón de Cuentos & $\begin{array}{l}\text { Uso de imágenes o dibujos para } \\
\text { describir o contar historias }\end{array}$ \\
\hline Comprensión de lectura & Creación de textos & $\begin{array}{l}\text { Dramatizaciones de las obras } \\
\text { leídas o por leer }\end{array}$ \\
\cline { 1 - 2 } $\begin{array}{l}\text { Conversatorios sobre cuentos } \\
\text { u otras obras literarias leídas }\end{array}$ & Trazo de las letras & Elaboración de cuentos, poesías \\
\cline { 1 - 2 } $\begin{array}{l}\text { Construcción o implementación } \\
\text { de nuevo vocabulario }\end{array}$ & $\begin{array}{l}\text { Uso de imágenes y sonidos para el } \\
\text { reconocimiento de letras o palabras }\end{array}$ & \multirow{2}{*}{ Autocorrección de redacciones } \\
\cline { 1 - 2 } Escuchar cuentos & $\begin{array}{l}\text { Extraer ideas principales o moralejas } \\
\text { de cuentos u otras lecturas }\end{array}$ & \\
\hline
\end{tabular}

Nota. Elaboración propia 
Revista Universidad en DiÁlogo • Vol. 11, N. ${ }^{\circ}$ 1, Enero-Junio, 2021 • 61-102

ISSN 2215-2849 • EISSN: 2215-4752

URL: http://www.revistas.una.ac.cr/index.php/dialogo/index CorReo ElECTRÓNICO: universidadendialogo@una.cr DOI: http://doi.org/10.15359/udre.11-1.3

En cuanto a la pregunta número 7: ¿Cómo considera usted quese puede asumir desde el programa de Español el enfoque de la educación inclusiva? Se percibe a través de las respuestas dos perspectivas, la primera corresponde a que existe una dificultad para atender de manera inclusiva la diversidad que existe en el aula escolar. A manera de ejemplo, se expone el comentario de una persona docente:

Es muy difícil, porque la inclusión es un tema que si a los docentes de aula le dieran las herramientas (capacitaciones, adecuación del aula, materiales, cantidad de estudiantes, etc.). Así que no estoy de acuerdo con la inclusión si son casos que demanden del tiempo específico con ese niño (a) con necesidades educativas especiales.

Por su parte, otras personas docentes conciben la inclusión como un proceso natural que acoge la diversidad en la que el ser humano se encuentra inmerso, de esta manera se presenta el siguiente comentario de un docente entrevistado:

Es importante saber que todos los estudiantes son diferentes, no se debe hacer un cambio significativo ya que siempre ha existido, solamente que hay que reforzar la ayuda para estos niños o niñas con alguna deficiencia. Por otro lado, conocer sus fortalezas será la clave para el progreso.

Como parte de esta concepción, otro docente comenta:

En el programa de español se prioriza el área oral, comunicativa y lingüística. La inclusión se basa principalmente en la socialización e integración de estos estudiantes con necesidades educativas especiales, entonces se favorece desde el momento en que estos estudiantes se sientan cómodos y puedan desarrollarse en un ambiente abierto al cambio y con actividades que le permitan el desarrollo de todos los contenidos.

La tabla 7 reúne algunas estrategias de inclusión mencionadas por las personas docentes entrevistadas:

En este apartado se retoma un punto importante mencionado por una docente, que señala que es realmente importante que los y las docentes se capaciten para obtener mejores herramientas y conocimientos sobre cómo desarrollar procesos de enseñanza y aprendizaje inclusivos, ya que en muchas ocasiones se sigue integrando a la población estudiantil con necesidades educativas especiales, mas no incluyéndola correctamente en el proceso de aprendizaje. 
URL: http://www.revistas.una.ac.cr/index.php/dialogo/index

CORREO ELECTRÓNICO: universidadendialogo@una.cr

DOI: http://doi.org/10.15359/udre.11-1.3

\section{Tabla 7}

Estrategias de inclusión a través del programa de Español

\begin{tabular}{|l|l|}
\hline \multicolumn{2}{|c|}{ Estrategias de inclusión a través del programa de Español } \\
\hline $\begin{array}{l}\text { Emplear estrategias de mediación acordes } \\
\text { con las necesidades del estudiantado }\end{array}$ & $\begin{array}{l}\text { Facilitar materiales que complementen } \\
\text { o guíen de una mejor manera el } \\
\text { proceso de aprendizaje del estudiantado }\end{array}$ \\
\hline $\begin{array}{l}\text { Contar con el apoyo de un o una docente de } \\
\text { Educación Especial }\end{array}$ & $\begin{array}{l}\text { Fomentar en el aula la convivencia y } \\
\text { el respeto por la diversidad }\end{array}$ \\
\hline $\begin{array}{l}\text { Implementar, mediante los temas transversales } \\
\text { y las diversas lecturas, los temas relacionados } \\
\text { con la diversidad y la inclusión }\end{array}$ & $\begin{array}{l}\text { Proveer ambientes de motivación, } \\
\text { seguridad y un ambiente confortable } \\
\text { para el estudiantado }\end{array}$ \\
\hline $\begin{array}{l}\text { Promover una participación } \\
\text { activa del estudiantado }\end{array}$ & $\begin{array}{l}\text { Conocer las fortalezas del estudiantado } \\
\text { para incentivar su progreso }\end{array}$ \\
\hline Propiciar trabajos colaborativos y grupales & Realizar actividades de integración \\
\hline $\begin{array}{l}\text { Ajustar actividades cuando se } \\
\text { considere necesario }\end{array}$ & $\begin{array}{l}\text { En caso de requerirlo, aplicar las } \\
\text { adecuaciones educativas al estudiantado }\end{array}$ \\
\hline $\begin{array}{l}\text { Asignar un compañero tutor o una } \\
\text { compañera tutora }\end{array}$ & $\begin{array}{l}\text { Propiciar un aprendizaje integrado } \\
\text { con otras asignaturas para un mejor } \\
\text { entendimiento de las temáticas }\end{array}$ \\
\hline
\end{tabular}

Nota. Elaboración propia

Finalmente, se exponen los datos recopilados sobre la pregunta número ocho: ¿Cuáles estrategias se están utilizando para articular curricularmente el programa de Español con las asignaturas básicas de Matemática, Estudios Sociales y Ciencias?

A partir de las respuestas se constata que la mayoría de las personas docentes articulan el programa de Español con las demás asignaturas básicas a través de la implementación de las diversas habilidades de comunicación requeridas para el desempeño y el desarrollo de aprendizaje a lo largo del ciclo escolar, estas son: la comprensión lectora, la expresión oral y la expresión escrita. Así lo exponen algunas docentes: 
Básicamente ninguno, yo creería que en donde uno puede hacer una articulación es en comprensión de lectura, o cuando se ve la temática de ortografía y usted hace alguna lectura o copia en la pizarra y les recuerda chicos vean aquí se escribe así por tal razón, pero no se trabaja para ponerse de acuerdo con algún tema. Principalmente en español, porque este programa es muy específico, viene muy puntual, a mí en lo personal me limita un poco unirlo con otra materia, digamos Estudios Sociales con Ciencias es muy fácil complementarlo, pero en español utilizo la cotidianidad.

Otra persona entrevistada indica lo siguiente:

En realidad, todas las materias están integradas con la materia de español, por lo que el niño que tiene un buen nivel en lectoescritura se le facilita la comprensión y análisis de un problema matemático, la comprensión de la historia, la lectura del sistema digestivo entre algunos ejemplos que se pueden citar. Por lo tanto, si estoy estudiando sustantivos y adjetivos puedo redactar oraciones de cada órgano y su función donde se encuentran los sustantivos y adjetivos, o señalar en una lectura del tema estos contenidos.

La siguiente tabla muestra de forma sistematizada algunas estrategias utilizadas por docentes para la articulación curricular del programa de Español con otras materias básicas.

\section{Tabla 8}

Estrategias para articular curricularmente el programa de Español con otras materias básicas

\begin{tabular}{|l|l|}
\hline \multicolumn{2}{|l|}{ Estrategias para articular curricularmente el programa de Español con otras materias básicas } \\
\hline Comprensión lectora & Expresión escrita \\
\hline Promoción de la expresión oral y de la escrita & Mejoramiento de la ortografía \\
\hline Investigaciones & Escritura \\
\hline Procesos de razonamiento, argumentación y comunicación & Exposiciones \\
\hline Divulgar resultados o conocimientos & $\begin{array}{l}\text { Lectura aplicada al contenido } \\
\text { de cada asignatura }\end{array}$ \\
\hline Resolución de problemas matemáticos & Conversatorios \\
\hline
\end{tabular}

Nota. Elaboración propia 
URL: http://www.revistas.una.ac.cr/index.php/dialogo/index

CORREO ELECTRÓNICO: universidadendialogo@una.cr

DOI: http://doi.org/10.15359/udre.11-1.3

Tal como lo expone una docente, el programa de Matemáticas plantea varios momentos, entre ellos: razonar y argumentar, plantear y resolver problemas, comunicar y conectar; entonces, a través de estos espacios, el estudiantado integra los conocimientos y las competencias aplicados también en la asignatura de Español, de manera que los saberes se ponen en práctica de una forma integrada.

Razonar y argumentar se trata de actividades mentales que aparecen transversalmente en todas las áreas del plan de estudios y que desencadenan formas típicas del pensamiento matemático: deducción, inducción, comparación analítica, generalización, justificaciones, pruebas, uso de ejemplos y contraejemplos. Busca desarrollar capacidades para permitir la comprensión de lo que es una justificación o prueba para desarrollar y discutir argumentaciones matemáticas, para formular y analizar conjeturas matemáticas, para usar fórmulas o métodos propios de esta asignatura, que permitan la comprensión o desarrollo de informaciones presentes (...) Comunicar: Es la expresión y comunicación oral, visual o escrita de ideas, resultados y argumentos matemáticos al docente o a los otros estudiantes. Este proceso busca potenciar la capacidad para expresar ideas matemáticas y sus aplicaciones usando el lenguaje matemático (reglas de sintaxis y semántica) de manera escrita y oral con otros estudiantes, docentes y a la comunidad educativa. Pretende que se desarrollen capacidades para consignar y expresar con precisión matemática las ideas, los argumentos y procedimientos utilizados, así como las conclusiones a las que se haya llegado e identificar, interpretar y analizar las expresiones de esta asignatura, escritas o verbales, realizadas por otras personas.

En su mayoría, las estrategias que son desarrolladas por los y las docentes en las demás asignaturas se vinculan con el área de español a nivel sintáctico, morfológico y ortográfico, así como con el proceso de lectoescritura, de manera que conciben que la articulación de los programas se enfoca en la aplicación correcta de estructuras y el fortalecimiento de la lectura, la escritura y las formas de expresión escrita y oral.

Las diversas competencias comunicativas de las y los estudiantes son la base fundamental para que se desenvuelvan activamente en el proceso de aprendizaje de las demás asignaturas, pues, tal como lo mencionan algunas personas docentes, en las demás materias se requieren la escritura y la expresión oral y escrita, por ejemplo en Estudios Sociales o Ciencias, donde se realizan exposiciones de las diversas temáticas; por ende, el estudiantado integra las habilidades desarrolladas a partir de los conocimientos en Español. 
Revista Universidad en DiÁlogo • Vol. 11, N. ${ }^{\circ}$ 1, Enero-Junio, 2021 • 61-102

ISSN 2215-2849 • EISSN: 2215-4752

URL: http://www.revistas.una.ac.cr/index.php/dialogo/index CorReo ElECTRÓNICO: universidadendialogo@una.cr DOI: http://doi.org/10.15359/udre.11-1.3

\section{Conclusiones}

La adquisición de la lectoescritura en primaria es la puerta de entrada al currículo escolar, de ahí su trascendencia e importancia. Sin saber leer y escribir no se accede, ni remotamente, a la cultura contemporánea.

En este sentido, de acuerdo con el VII Informe del Estado de la Educación 2019, en lo concerniente a la educación primaria, y con las respuestas de los y las docentes que participaron en la entrevista, se constata la existencia de un poco reconocido problema que choca de frente, y no sin cierta virulencia, con el imaginario nacional de ser el bastión por excelencia de la educación pública nacional. Fundamentan tal afirmación en el hecho de que "casi el 94\% de nuestros niños y niñas asisten a instituciones que no imparten el currículo completo y, además la calidad de la enseñanza en las aulas dista mucho de los parámetros exigidos por el MEP” (p. 29).

Plantean una serie de desafíos: en materia de acceso ha bajado la cobertura de un $97 \%$, en el período 2005-2011, a un 93,1\% en la hora actual; con respecto a la universalización del currículo, el documento aboga por un cambio estructural en el modelo de gestión de la enseñanza primaria, a favor de uno basado en menos escuelas, de mayor matrícula y concentración del personal docente y con posibilidad de ofrecer el currículo completo con buenas infraestructuras y nuevas tecnologías digitales.

Otro punto relevante es que la reforma curricular, llevada a cabo por el MEP en los últimos años con respecto a los nuevos planes, se complementa con un acompañamiento a los y las docentes en su implementación, ya que se opera un viraje fundamental de óptica en el abordaje: de un currículo por contenidos a uno de habilidades.

Se plantea además en el Informe la necesidad de que los maestros y las maestras de primer grado continúen impartiendo clases con el mismo grupo en segundo grado, a fin de que el proceso de adquisición de la lectoescritura fluya sin contratiempos, ya que es la base para poder asimilar el resto de los conocimientos de las materias básicas.

Aboga además, en materia de formación docente, por un marco nacional de cualificaciones de los maestros y las maestras de primaria (proceso en marcha) que sirva de base para que el MEP contrate a futuras personas funcionarias. Reconoce también la imperiosa necesidad de que las universidades, como formadoras de 
personas formadoras, realicen un trabajo colaborativo junto al MEP para garantizar una reforma curricular real en las aulas, que privilegie una mejora sustantiva de las habilidades lingüísticas y comunicacionales de los niños y las niñas.

A continuación, se detallan los principales hallazgos del Informe: baja en la cobertura; disminución de matrícula en los centros escolares en función del bono demográfico; la no oferta del currículo completo en un 93,7\% de las escuelas; un $74 \%$ de las y los docentes ve la lectura como una práctica obligatoria desligada del gusto y del placer; y solo un $32 \%$ se siente preparado para la enseñanza de la lengua.

Además de este desolador panorama, se suma el hecho de que el vínculo MEP-universidades públicas y privadas es prácticamente inexistente, sobre todo con las privadas. La apertura a la privatización en materia de formación docente, que se viene implementando desde 1985, ha provocado una pérdida de soberanía educativa muy alarmante para el futuro de la educación primaria pública a nivel nacional.

A continuación, se enumeran las principales temáticas abordadas en el Informe:

1. Cambio demográfico sobre la matrícula de primaria, debido a la menor cantidad de niños y niñas que asisten a ese nivel.

2. Aumento del rezago escolar e incremento de las adecuaciones curriculares en segundo grado

3. Solo el $50 \%$ de los y las docentes tiene el perfil requerido para aplicar la reforma del programa de Español.

4. Predominio de prácticas tradicionales y una concepción de la lectura como algo ajeno al placer

5. Débil formación inicial de los y las docentes, que afecta la aplicación del programa de Español.

Con el fin de atender los retos que enfrenta la educación nacional, la Oficina de Planificación de la Educación Superior plantea en el documento Desafíos de la Educación en Costa Rica y aportes de las universidades públicas (2019), elaborado por el Programa de Estado de la Educación a solicitud de Conare, las siguientes dificultades que considera esenciales en función de cuatro ejes temáticos: 


\section{Acceso al sistema}

2. Calidad de los y las docentes

3. Ambientes de aprendizaje e infraestructura

4. Gestión del sistema

En este sentido y en relación con la educación primaria, se reitera en el documento analizado la necesidad de mejorar sustancialmente la formación docente inicial en las universidades. Destaca que de las 10000 personas profesionales que se gradúan por año, el $70 \%$ proviene de las universidades privadas, casi todas sin procesos de acreditación, dado que solo $6,7 \%$ están acreditadas frente al Sinaes, sin que medien en la selección de los y las estudiantes requisitos de ingreso ni procesos de selección según aptitudes e idoneidad para ejercer la docencia.

Otro dato relevante es que más del $50 \%$ del cuerpo docente en servicio se graduó de universidades privadas. Al momento de contratar, se hace en función de la titulación, sin que medie ningún proceso que permita saber si las personas contratadas poseen los conocimientos y las habilidades para aplicar los nuevos planes vigentes en el MEP.

Se constata en el documento la necesidad manifiesta de atraer, contratar y retener a las personas docentes más talentosas. No existe hoy en el MEP ningún proceso de selección de ingreso, dado que no posee un perfil para contrastar requisitos. Menciona que el MEP tampoco tiene un mecanismo de inducción, acompañamiento formativo y formación continua sólida que les permita a los y las docentes procesos de actualización permanente.

Respecto a los ambientes de aprendizaje e infraestructura, se insta de manera efectiva a aplicar la reforma curricular del MEP y modificar lo que realmente pasa en el aula, es decir, a reducir la brecha entre los planteamientos de la nueva Política Educativa y las prácticas de enseñanza en las aulas, que nos permitiría, entre otros asuntos, mejorar el desempeño de nuestro estudiantado en las pruebas PISA y FARO.

Universalizar el currículo de primaria y mejorar los aprendizajes de los y las estudiantes se impone como otro reto impostergable, dado que cerca de un 17 $\%$ de los niños y las niñas no está llegando a sexto grado en el tiempo esperado y un $9 \%$ presenta problemas por sobreedad. Solo un $7 \%$ de las escuelas a nivel 
URL: http://www.revistas.una.ac.cr/index.php/dialogo/index

CORREO ELECTRÓNICO: universidadendialogo@una.cr

DOI: http://doi.org/10.15359/udre.11-1.3

nacional reciben la totalidad de las materias del currículo oficial. También se propone incrementar la calidad de la infraestructura en los centros educativos, así como lograr el $100 \%$ de conectividad con banda ancha.

Asegura el documento que los compromisos en relación con las políticas docentes se fundamentan en los siguientes puntos, a saber:

1. Contribuir a elaborar un Marco Nacional de Cualificación Docente, que contendrá estándares nacionales sobre formación docente inicial.

2. Colaborar en la formulación de los perfiles docentes que el MEP requiere contratar, en función de los datos que proporcionan los nuevos planes de estudio.

3. Diseñar pruebas de idoneidad docente para su aplicación por parte del Servicio Civil

4. Apoyar al MEP en la elaboración de instrumentos para fortalecer la evaluación formativa

5. Crear un programa de Mentores Universitarios para apoyar a los y las docentes en las aulas

En este contexto surgen, sin lugar a dudas, puntos de contacto entre los hallazgos de las observaciones realizadas por el grupo de investigadores e investigadoras del Estado de la Educación 2019 y la sistematización de nuestras entrevistas. Mientras que las primeras pretenden un abordaje más macro y general en relación con el Ministerio de Educación, como institución pública que rige los destinos de la educación a nivel nacional, las opiniones de los y las docentes que resultan de nuestras entrevistas se refieren de manera concreta a la implementación del Plan de Español en la realidad cercana e inmediata del aula escolar.

Sin embargo, constatamos, sin ningún atisbo de sorpresa, que los planteamientos coinciden: brindar capacitación sobre el nuevo abordaje del currículo por habilidades, dar acompañamiento y asesoramiento metodológico en el marco de una educación inclusiva y del Diseño Universal de Aprendizaje (DUA), fomentar el trabajo colaborativo de los equipos docentes, otorgando tiempos y espacios para llevarlo a cabo, y coordinar con las universidades y entidades encargadas de la formación docente, a fin de establecer parámetros compartidos acerca de la enseñanza de la lectoescritura. 
La voz del cuerpo docente, expresada en las respuestas a nuestras interrogantes, debe necesariamente llamarnos a la reflexión, tanto al Ministerio de Educación Pública como a las universidades formadoras. En última instancia, solo se trata de prever, organizar y planificar con criterio de política pública y en aras del bienestar general. Nuestra población infantil tiene derecho a aprender. Está en juego su futuro y dignidad, no la defraudemos.

\section{Referencias}

Consejo Nacional de Rectores. (2019). Desafíos de la educación en Costa Rica y aportes de las universidades públicas. Programa Estado de la Nación, San José.

Forteza, L. (2017). Experiencias- La potencia de una metodología-Un colectivo docente en movimiento. Montevideo: Colectivo Docente

Ministerio de Educación Pública. (2017). Política Educativa- La persona: centro del proceso educativo y sujeto transformador de la sociedad. San José, Costa Rica.

Ministerio de Educación Pública. (2015). 15 orientaciones estratégicas institucionales. San José, Costa Rica.

Pérez-Gomar, G. (2013). Cambiar la educación: ente deseos y realidades. De las políticas educativas a las prácticas pedagógicas. Montevideo: Editorial Magró.

Terigi, F. (2006). Diez miradas sobre la escuela primaria. Buenos Aires: Siglo XXI. 